\title{
Recommendations for patients with chronic respiratory disease considering air travel: A statement from the Canadian Thoracic Society
}

\author{
Dale Lien MD, Mark Turner MD and the Canadian Thoracic Society Standards Committee
}

\section{Lien, M Turner, Canadian Thoracic Society Standards Committee. Recommendations for patients with chronic respiratory disease considering air travel: A statement from the Canadian Thoracic Society. Can Respir J 1998;5(2):95-100.}

Patients with respiratory disease regularly seek the convenience of commercial airline travel. In addition to the stresses that all patients with chronic disease encounter, these patients are exposed to the affects of acute altitudinal hypoxemia. This in turn has the potential to produce significant symptoms and complications in-flight for patients with chronic respiratory disease. This article reviews the current literature, and seeks to help the practicing physician by providing recommendations on which patients should be assessed preflight, the type of assessment that should be carried out and recommendations for providing advice to these travelling patients.

Key Words: Air travel, Altitude, COPD, Guidelines, Hypoxemia, Oxygen therapy
Recommandations pour les malades pulmonaires chroniques souhaitant voyager par avion : prise de position de la Société canadienne de thoracologie

RÉSUMÉ : Pour des raisons de commodité, les malades pulmonaires chroniques envisagent souvent de voyager par avion. En plus du stress que tous les malades avec une affection chronique rencontrent généralement, les malades pulmonaires chroniques s'exposent également aux effets d'une hypoxémie aiguë due à l'altitude, et qui peut, au cours du vol, provoquer chez eux des symptômes et des complications importants. Le présent article passe en revue la littérature actuelle et souhaite aider le praticien en lui fournissant des recommandations concernant l'évaluation des patients avant un voyage par avion, le type d'évaluation à effectuer, et les conseils à donner à ces patients qui voyagent.
$\mathrm{T}$ his article was written to provide assistance to physicians faced with assessing patients with chronic respiratory disease who wish to travel by commercial airline. The following recommendations are proposed by the Canadian Thoracic Society Standards Committee after review of the English language literature, consultation with experts in the area, and critique by members of the Standards Committee.
Unfortunately, the state of the art is plagued by a lack of objective scientific data. Therefore, these recommendations are not supported by large, randomized, controlled trials, but rather reflect data from several small studies testing various interventions (1-10) and reviews by experts on the topic (1117). These recommendations will evolve with greater clinical experience and publication of new information.

*Canadian Thoracic Society Standards Committee: Drs Robert Hyland, Chairman, Meyer Balter, Dennis Bowie, Pierre Leblanc, Dale Lien, Mark Turner

Correspondence: Dr Dale Lien, 2E4.33 WCMHSC, University of Alberta, Edmonton, Alberta T6G 2B7. Telephone 403-492-4862, fax 403-492-6384 


\section{SCOPE OF THE PROBLEM}

Air travel has become a preferred mode of travel with an estimated more than 12 million passengers per year travelling on commercial airlines in Canada (18). Although no accurate statistics are available, it is reasonable to estimate that a percentage of these travellers have chronic cardiac or respiratory disease as the prevalence of chronic obstructive pulmonary disease (COPD) alone approaches $3 \%$ to $5 \%$ in the population $(4,17)$. With increasingly proactive attitudes coupled with advances in drug therapy, oxygen delivery systems and rehabilitation programs, increasing numbers of patients are seeking the freedom of air travel. While patients with any chronic disease frequently encounter logistical problems while travelling, those with respiratory disease may have the added problem of acute altitudinal hypoxemia $(1,6,16,17$, 19-22). Although many patients with severe disease have chronic hypoxemia at ground level, others with milder disease may only become hypoxemic when exposed to the lower ambient partial pressure of oxygen that occurs during commercial air travel.

The patient with chronic respiratory disease may encountered many potential barriers to successful air travel. Some of the major obstacles are the physiological effects of exposure to hypobaric hypoxemia, additive effects of medications, the physical stress and fatigue of travel, disruption of usual schedules, increased costs of travel, necessity of arranging for a travel companion, logistics of transporting respiratory equipment and oxygen, and difficulties in arranging for and the cost of in-flight oxygen. In this review, we will focus on the problem unique to the patient with respiratory disease, which is the effect of acute hypobaric hypoxemia. In doing so, we will provide general recommendations for the assessment and treatment of patients with respiratory disease considering air travel.

\section{PHYSIOLOGICAL EFFECTS OF AIR TRAVEL} Effect of commercial air flight on ambient partial pressures of oxygen: Commercial jet aircraft vary in their routine cruising altitudes from $6700 \mathrm{~m}$ to $13,400 \mathrm{~m}$ above sea level. Although the interior of the cabins is partially pressurized, cabin pressures are not maintained at ground level equivalents because of concerns with operating efficiency, structural integrity (frequent pressurization-depressurization cycles can weaken the aircraft structure) and cost effectiveness. The maximum amount of cabin pressurization capacity is fixed on a given aircraft and is generally greater in newer aircraft, which are designed to fly at higher altitudes (2). Cottrell (3) used altimeters to measure effective in-flight cabin altitudes on 16 different types of aircraft during 194 American domestic and 10 intercontinental, regularly scheduled commercial flights. The mean in-flight cabin altitude was $1724 \pm 615 \mathrm{~m}$ (mean $\pm \mathrm{SD}$ ) with a median of $1894 \mathrm{~m}$. There were significantly higher pressures in newer generation aircraft (median 2259 metres) versus older generation aircraft (median 1846 metres). Hence, at normal cruising altitudes, cabin pressures may range from 565 to $690 \mathrm{mmHg}$. Once the plane is airborne, the cabin pressure may not remain constant while the aircraft changes altitudes to avoid turbulence. Therefore, preflight prediction of cabin pressures is approximate at best.

Although the proportion of oxygen in ambient air always remains constant, at approximately $21 \%$, the falling barometric pressure with increasing altitude results in lower $\mathrm{PO}_{2}$. The $\mathrm{PO}_{2}$ in inspired air falls approximately $4 \mathrm{mmHg}$ for every $300 \mathrm{~m}$ of altitude (17). An effective cabin altitude of 1724 metres results in an inspired $\mathrm{PO}_{2}$ of $118 \mathrm{mmHg}$ compared with $149 \mathrm{mmHg}$ at sea level. However, the wide range of inflight cabin pressures noted by Cottrell (3) means that inspired oxygen pressures may vary from 106 to $135 \mathrm{mmHg}$. In a subject with normal respiratory function, this means that the $\mathrm{PO}_{2}$ in arterial blood $\left(\mathrm{PaO}_{2}\right)$ will change from approximately $100 \mathrm{mmHg}$ at sea level to 55 to $85 \mathrm{mmHg}$ during commercial air flight (assuming normocapnia). Although these effects on the partial pressures of oxygen in the blood of normal subjects are known, there has been relatively little investigation into how this environment affects patients with compromised respiratory function.

Physiological effects on patients with chronic respiratory disease: The ascent to high altitude results in reduced inspired oxygen pressure with an associated decrease in $\mathrm{PaO}_{2}$. Normal subjects adapt very quickly to this hypoxemia by increasing minute ventilation (primarily by increasing tidal volume) and correcting $\mathrm{PaO}_{2}(12,14,17,19,20,23-25)$. However, patients with acute or chronic lung disease, whose $\mathrm{PaO}_{2}$ is already low and on the steep portion of the oxyhemoglobin dissociation curve at ground level, may not have the reserve to increase ventilation, which may leave them significantly hypoxemic in-flight. The situation may be further worsened by exertion, hypoxemia-induced pulmonary hypertension resulting in decreased cardiac output, low ambient humidity causing difficulty with drying of secretions, fatigue and sleep deprivation, hypoventilation during sleep, exposure to cigarette smoke and carbon monoxide, and the effects of alcohol, sedatives and medications.

However, despite the potential risks, there is little objective data on the incidence of hypoxemia and hypoxemiainduced symptoms and complications in patients with lung disease travelling on commercial airlines. In part, this may be because the exposure to hypoxic conditions for most travellers is brief, lasting only a few hours at most, and the early symptoms of hypoxemia such as dyspnea, euphoria, impaired judgement and mental confusion are often subtle and may go unreported. It also appears that true emergencies are relatively rare. Skjenna et al (18) reviewed medical incidents requiring a nurse, physician or paramedic on board Air Canada flights from 1982 to 1988 and found that from 221 to 464 incidents occurred per year with an average of 2.9 deaths per year. Cardiovascular disease was by far the most common problem, with respiratory disease accounting for approximately $10 \%$ of these incidents. Speizer et al (26) surveyed passenger arrivals at Los Angeles International Airport and found that $260(0.003 \%)$ of 8.7 million arrivals had significant in-flight medical problems. Twelve of these patients had exacerbations of COPD. Cummins et al $(27,28)$ in an eight- 
year survey of 42 international airlines found reports of 577 in-flight deaths, of which $56 \%$ were reported as cardiac related and $6 \%$ were classified as respiratory related. The information gathered in these studies was retrospective and incomplete, and it is not known what proportion of these patients were chronically hypoxemic or required oxygen supplementation.

In addition to these clinical observations, several scientific studies examining the effects of either hypobaric hypoxemia (1) or normobaric hypoxemia $(4,27)$ did not report significant adverse clinical events. However, these studies used selected small numbers of stable patients and studied them for relatively brief periods of $1 \mathrm{~h}$ or less. These subjects did not have additional stresses such as fatigue, sleep deprivation, medication or exercise. Unfortunately, evaluating patients for the effects of hypoxemia can be difficult. The initial effects of hypoxia are often insidious, with euphoria and decreased cognitive function occurring some time before more overt findings such as seizures or loss of consciousness. Individual tolerance may also vary considerably, while smoking, cardiac disease, anemia, alcohol and some drugs can potentiate or confuse the effects. A theoretical but undocumented risk is the possibility of hypoxemia induced cardiac arrhythmias occurring during the flight. At this point, there is a need for methodologically sound prospective evaluation.

Prediction of in-flight $\mathbf{P a O}_{\mathbf{2}}$ : The $\mathrm{PaO}_{2}$ while in-flight is probably the most important factor determining the ability of the patient with chronic lung disease to fly safely. While this has lead to considerable interest in the accurate prediction of in-flight $\mathrm{PaO}_{2}$, the measured in-flight $\mathrm{PaO}_{2}$ is determined not only by the altitude, but by the patient's ability to respond appropriately by increasing ventilation. In addition, other complicating factors such as fatigue, sleep deprivation, alcohol, medications, etc, make accurate prediction extremely difficult. However, a number of studies have attempted to address this issue using several techniques including actual measurements in-flight, hypobaric chambers in the laboratory, and by inhalation of hypoxic gas mixtures in the laboratory $(1,4,5,29)$, with the majority of studies carried out on subjects with stable COPD.

Several investigators have studied the use of regression equations as a means of predicting in-flight $\mathrm{PaO}_{2}$ in stable groups of patients with COPD and restrictive lung disease $(1,5,29)$. Gong et al (29) studied the effects on patients with respiratory disease who inhaled oxygen concentrations of $17 \%, 15 \%$ and $14 \%$ which correspond to the ambient $P_{2}$ experienced at $1500 \mathrm{~m}, 2400 \mathrm{~m}$ and $3000 \mathrm{~m}$, respectively. A regression equation proposed by these investigators for patients with stable COPD is

$$
\text { altitude } \mathrm{PaO}_{2}=22.8-2.74 \mathrm{x}+0.68 \mathrm{y}
$$

where $\mathrm{x}$ is altitude in thousands of feet and $\mathrm{y}$ is sea level $P_{\mathrm{aO}}$. A similar predictive equation for patients with restrictive lung disease proposed is

$$
\text { altitude } \mathrm{PaO}_{2}=25.0-3.12 \mathrm{x}+0.62 \mathrm{y}
$$

Dillard et al (1) studied 18 patients with emphysema (forced expiratory volume in $1 \mathrm{~s}\left[\mathrm{FEV}_{1}\right]=0.97 \pm 0.32 \mathrm{~L}$ ) and nine normal subjects using a hypobaric chamber comparing sea level with a simulated altitude of $2400 \mathrm{~m}$ (barometric pressure $565 \mathrm{mmHg}$ ). At sea level, the COPD patients had a $\mathrm{PaO}_{2}$ of $72.4 \pm 9 \mathrm{mmHg}$ with a fall to $47.4 \pm 6 \mathrm{mmHg}$ at altitude while $\mathrm{PaCO}_{2}$ was $38 \pm 4 \mathrm{mmHg}$ at sea level and $35 \pm 4 \mathrm{mmHg}$ at altitude. Normal subjects had a fall in arterial $P_{2}$ from $95.6 \pm 8 \mathrm{mmHg}$ at sea level to $59.8 \pm 4 \mathrm{mmHg}$ at altitude with a $\mathrm{PaCO}_{2}$ of $39 \pm 4 \mathrm{mmHg}$ at sea level and $34 \pm 4 \mathrm{mmHg}$ at altitude. No patients developed significant symptoms at altitude for 45 mins, and the best fit equation to describe the regression was

$\mathrm{PaO}_{2}$ at altitude $=0.410\left(\mathrm{PaCO}_{2}\right.$ at sea level $)+17.652$

They also found $\mathrm{FEV}_{1}$ to have additional predictive value. Others $(5,29)$ have also tried to develop regression formulas to predict $\mathrm{PaO}_{2}$ at altitude; however, their complexity limits their practical use. Predictive equations may also be influenced by factors such as timing of arterial blood gas samples because Schwartz et al (4) demonstrated that measurement of ground level $\mathrm{PaO}_{2} 2 \mathrm{~h}$ before flight gave a better predictive value than measurements made weeks before. If predictive equations are to be used, a ground level blood gas should probably be determined within days of travel in a clinically stable patient. Prediction equations may ultimately prove useful for selected patients; however, they are limited to specific conditions and cannot account for unexpected variations in effective cabin altitude or other complicating factors. They do not predict $\mathrm{PaO}_{2}$ during in-flight exertion and are not accurate for patients with hypercapnia or who are already on supplemental oxygen. More important, they remain to be validated in the general population.

From a clinical perspective, the most practical objective preflight evaluation is probably obtained by assessing the patient while he or she is breathing hypoxic gas mixtures in a pulmonary function laboratory or monitoring in a hypobaric chamber. Such testing also allows measurement of the amount of supplemental oxygen required to maintain adequate oxygenation in-flight. Although hypobaric chambers are an attractive method, their lack of availability makes them inaccessible to most physicians. A practical alternative is to monitor oxygenation by pulse oximetry or arterial blood gases while breathing a hypoxic gas mixture containing $15 \%$ oxygen, which corresponds to an altitude of $2400 \mathrm{~m}$ $(4,17,29)$. Assessment for this altitude is recommended as a worst case scenario for commercial air travel.

\section{ROLE OF THE PHYSICIAN}

The role of the physician is to provide advice to prospective air travellers with the objective of preventing untoward difficulties during flight. Patients at risk for problems during air travel need to be identified, appropriately evaluated, and prescribed the necessary treatments to prevent problems from arising in-flight. It then becomes the responsibility of the patient to make the necessary arrangements to fulfil the airline's requirements and the responsibility of the airline to ensure the safety of the patient and other passengers during flight.

\section{RECOMMENDATIONS}

Who to evaluate before air travel: The following patients should be considered for evaluation (Table 1).

- Patients with known or suspected hypoxemia 


\section{TABLE 1}

\begin{tabular}{l} 
Whom to evaluate for potential hypoxemia before air \\
travel \\
\hline Patients with known or suspected hypoxemia \\
Patients with known or suspected hypercapnia \\
Patients with known chronic obstructive lung disease or restrictive \\
lung disease \\
Patients who already use supplemental oxygen \\
Patients with a history of previous difficulty during air travel \\
Patients with recent exacerbation of chronic lung disease \\
Patients with other chronic conditions that may be exacerbated \\
by hypoxemia
\end{tabular}

Patients with a documented $\mathrm{PaO}_{2}$ of less than $70 \mathrm{mmHg}$ at sea level (or equivalent for their local altitude) should be evaluated for supplemental in-flight oxygen because these patients will have a predicted in-flight arterial oxygen tension of 50 to $55 \mathrm{mmHg}$ or less.

- Patients with known hypercapnia

Although the risk associated with hypercapnia has not been systematically studied, intuitively these patients are at higher risk. A study evaluating 21 patients who flew a commercial airline to centres for lung transplantation or thromboembolectomies (4) reported seven patients who had a $\mathrm{PaCO}_{2}$ greater than $40 \mathrm{mmHg}$ (mean 48.8, SD 10.1). Of these patients, four had in-flight complications including two syncopal episodes, one with persistent hypoxemia not responding to oxygen supplementation, and one death. Of the 14 nonhypercapneic patients, only one patient had a complication that was a syncopal episode. Hypercapneic patients requiring oxygen supplementation may be at even greater risk if they require increased oxygen supplementation in-flight.

- Patients with known COPD or restrictive lung disease with impaired lung function

Lung function studies indicating significant physiological impairment suggest a significant risk of hypoxemia and identify a need for objective measurement of oxygenation (1).

- Patients with known chronic hypoxemia requiring supplemental oxygen

Patients already requiring supplemental oxygen require re-evaluation before travel. In general, these patients require an increase in the supplemental oxygen flows by 1 to $3 \mathrm{~L} / \mathrm{min}$ $(12,13)$.

- Patients with a past history of possible hypoxemia-related symptoms during air travel

These symptoms might include dyspnea, chest congestion, syncope or nonspecific symptoms, such as lightheadedness, confusion or weakness.

- Patients with recent exacerbations of chronic lung disease

A review of a large American-based airline over 90 days in 1991 identified 233 patients that were required by the airline to have a medical evaluation (24). Of these, $85 \%$ required in-flight oxygen. Fifty-two patients (22\%) had been discharged from an acute care hospital within the two weeks

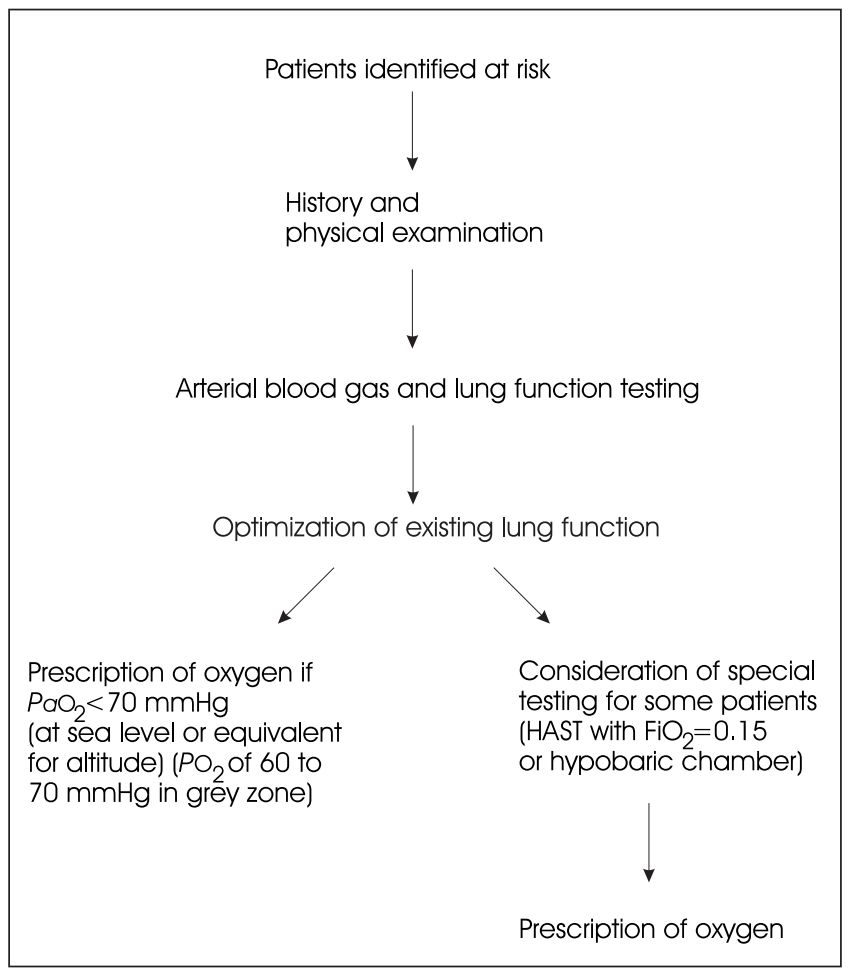

Figure 1) Assessment of patients who have been identified as potentially hypoxemic during air travel. $\mathrm{FiO}_{2}$ Fraction of inspired oxygen; HAST Hypoxia-altitude simulation test

before flying and had a disproportionately higher incidence of in-flight difficulties than the remaining patients.

- Patients with other chronic conditions that may be aggravated by hypoxemia such as cerebrovascular disease, coronary artery disease, or chronic cardiac failure.

Preflight evaluation: For patients who are identified as being at increased risk, the preflight evaluation should include a history and physical examination, measurement of arterial blood gases, lung function testing and special testing in selected cases (Figure 1).

- Clinical evaluation

The clinical history and examination provide the basic information that may lead to a recognition of risk factors if already not known, as well as any recent change in the status of an already known condition. A history of good exercise tolerance and recent uncomplicated air travel intuitively suggests a low risk for in-flight complications while a previous history of in-flight symptoms should raise the index of suspicion.

- Arterial blood gas measurements

Ground level arterial blood gases provide the best clinical predictor of in-flight blood oxygen tension. They have their best predictive value when measured as close to the travel date as possible (4). Although commercial aircraft aim to pressurize their cabins to an equivalent of $1800 \mathrm{~m}$ above sea level, available data suggest that this can vary (3) and preparations for a worst case scenario of $2400 \mathrm{~m}$ should be made. This corresponds to an approximate barometric pressure of 
$565 \mathrm{mmHg}$; normal subjects will have a drop in $\mathrm{PaO}_{2}$ from 100 to $59 \mathrm{mmHg}$ when moving from sea level to this altitude assuming normocapnia. However, the usual compensatory response is hyperventilation, which causes some increase in the $\mathrm{PaO}_{2}$. For practical purposes, patients with a $\mathrm{PaO}_{2}$ of greater than $70 \mathrm{mmHg}$ at sea level or equivalent for their altitude are unlikely to have difficulties $(4,5,17)$. The clinical application of predictive equations based on ground level $\mathrm{PaO}_{2}$ and anticipated flying altitude $(1,4,29)$ has already been discussed.

\section{- Lung function testing}

Objective measurements provided by pulmonary function testing provide an indicator of lung function and may identify patients who require more detailed evaluation. They may also be a general predictor of oxygenation (2) and provide a basis on which to optimize lung function before travel.

\section{- Special testing}

For selected patients who are at high risk or who have had previous complications during air travel, objective evaluation during simulated conditions of air travel may help assess the ability to respond physiologically, the symptoms that may be experienced and the results of oxygen supplementation. There are two approaches to laboratory testing: use of a hypobaric chamber and administration of hypoxic gas mixtures, also known as a hypoxia-altitude simulation test (HAST) $(4,13,17)$. Use of a hypobaric chamber is limited to a few laboratories, while the inhalation of a hypoxic gas mixture with a fraction of inspired oxygen $\left(\mathrm{FiO}_{2}\right)$ of 0.15 is a practical method that can be carried out in most pulmonary function laboratories. Coupled with simultaneous measurements of either oxygen saturations by pulse oximetry or arterial blood gases (as well as continuous electrocardiogram and physician monitoring), the effects of hypoxemia can be assessed, and, at the same time, supplemental oxygen requirements can be titrated. Novel approaches for carrying out a HAST test have been described and include a technique using a venturi mask with nitrogen as a source gas to lower oxygen tension (7) and lowering ambient oxygen tension in a sealed body plethysmograph (8). Ultimately, the most practical approach might be the use of increasingly affordable and portable pulse oximeters with which oxygen can be titrated in-flight by the patient or a travelling companion (9).

Recommendations for patients: In advising a patient with chronic respiratory disease who wishes to travel by commercial airline, the physician must use a combination of clinical judgement and the available data. In summary, a general approach for assessing the patient for air travel includes the following (Figure 1):

- Clinical assessment to determine risk factors and degree of impairment;

- Measurement of arterial blood gases and lung function as close as possible to the travel date;

- Optimization of the patient's existing lung function;

- Estimation of in-flight $\mathrm{PaO}_{2}$ and prescription for supplemental oxygen if required. In assessing the need for oxygen therapy, the goal should be to maintain a minimum $\mathrm{PaO}_{2}$ of 50 to $55 \mathrm{mmHg}$ during the flight. Patients with a sea level $\mathrm{PaO}_{2}$ of less than 70 $\mathrm{mmHg}$ are at increased risk for hypoxemia. The subgroup of these with a $\mathrm{PaO}_{2}$ between 60 and $70 \mathrm{mmHg}$ are in a grey zone depending on their estimated ability to compensate by hyperventilation. For those in whom hypoxemia is deemed probable, supplemental oxygen should be recommended. For patients who do not ordinarily require supplemental oxygen at ground level, the empiric addition of $2 \mathrm{~L} / \mathrm{min}$ should adequately correct potential hypoxemia $(7,8,17)$. For those on supplemental oxygen at ground level, an increase in the flow rate by 1 to 3 $\mathrm{L} / \mathrm{min}$ is recommended. For those in whom there is uncertainty, a hypoxic gas study (eg, HAST) using an $\mathrm{FiO}_{2}$ of 0.15 in the pulmonary laboratory is recommended.

\section{PLANNING FOR AIR TRAVEL}

In addition, there is advice regarding the logistics of air travel that the physician may be able to provide. For example, a well planned itinerary is important to minimize layovers at other airports, and direct flights should be used whenever possible. The need for a travelling companion should be considered. The patient should request a seat close to the lavoratory to minimize exertion and difficulty with equipment in-flight. Patients may be responsible for supplying their own oxygen during layovers and at their destination, and must plan ahead by contacting their respiratory supply company. Patients should avoid overeating, maintain adequate hydration, ensure that they are well rested and avoid alcohol. Smoking flights should also be avoided; some overseas carriers still permit smoking in-flight. The costs associated with oxygen supplementation, airline arrangements and vendor supplies must also be considered in advance, and extra time must be given to make reservations and notify the airline of the intention to travel.

\section{ROLE OF THE AIRLINES}

Air carriers have recognized and accepted that in-flight oxygen therapy is both manageable and safe. However, many deficiencies and issues remain surrounding the use of inflight oxygen, and at present, each airline has its own policy regarding the use of oxygen in-flight. Most airlines require advance booking and assessment by a qualified physician and consideration of individual cases by its own medical department. Most airlines prefer to use their own in-flight oxygen systems consisting of either D type cylinders or oxygen concentrators with a nonrebreathing mask at set flow rates of either 2 or $4 \mathrm{~L} / \mathrm{min}$. The cost of this extra service varies considerably form airline to airline. Carriers that allow passengers to use their own equipment usually accept only the D type cylinder because of its manageable size.

At present, there is no uniform Canadian policy regarding oxygen use in commercial aircraft. However, beginning in 1995, the Accessible Transportation Directorate of the fed- 
eral Canadian Transportation Agency held a series of meetings and consultations with representatives of the airline industry, respiratory equipment suppliers, patient groups and other interested parties, with the objective of developing a uniform national policy for the use of medical oxygen on commercial airflights. This policy will include agreement on standardized procedures and equipment that will be acceptable for travel. The present goal of the commercial airline industry is to transfer the responsibility for the equipment and oxygen back to the traveller. A number of issues of concern remain to be addressed including integrity of traveller-owned oxygen cylinders, mechanisms of securing the equipment

\section{REFERENCES}

1. Dillard TA, Berg BW, Rajagopal KR, Dooley JW, Mehm WJ. Hypoxemia during air travel in patients with chronic obstructive pulmonary disease. Ann Intern Med 1989;111:362-7.

2. Aldrette JA, Aldrette LE. Oxygen concentrations in commercial aircraft flights. South Med J 1083;76:12-4.

3. Cottrell JJ. Altitude exposures during aircraft flight. Flying higher. Chest 1988;93:81-4.

4. Schwartz JS, Bencowitz HZ, Moser KM. Air travel hypoxemia with chronic obstructive pulmonary disease. Ann Intern Med 1984;100:473-7.

5. Henry JN, Krenis LJ, Cutting RT. Hypoxemia during aeromedical evacuation. Surg Gynecol Obstet 1973;136:49-53.

6. Mills FJ, Harding RM. Fitness to travel by air: Physiological considerations. Br Med J Clinical Research Ed 1983;286:1269-71.

7. Vohra P, Klocke RA. Detection and correction of hypoxemia associated with air travel. Am Rev Respir Dis 1993;148:1215-9.

8. Cramer D, Ward S, Geddes D. Assessment of oxygen supplementation during air travel. Thorax 1996;51:202-3.

9. Kramer MR, Jakobson DJ, Springer C, Donchin Y. The safety of air transportation of patients with severe lung disease. Experience with 21 patients requiring lung transplantation or pulmonary thromboendarterectomy. Chest 1995;108:1292-6.

10. Oades PJ, Buchdahl RM, Bush A. Prediction of hypoxemia at high altitude in children with cystic fibrosis. Br Med J 1994;308:15-8.

11. Gong H Jr. Advising patients with pulmonary diseases on air travel. Ann Intern Med 1989;111:349-51.

12. Gong H Jr. Advising COPD patients about commercial air travel. J Respir Dis 1984;5:28-39.

13. Gong H Jr. Air travel and patients with chronic obstructive pulmonary disease. Ann Intern Med 1984;100:595-7. (Edit)

14. Liebman J R, Lucas R, Moss A, Cotton E, Rosenthal A, Rattenberg H. Airline travel for children with chronic pulmonary disease. Pediatrics 1976;57:408-10.

15. Tisi GM. Air travel and the COPD patient. Pulm Perspect 1984;1:5-7.

16. Richards PR. The effects of air travel on patients with cardiovascular and respiratory disease. Practitioner 1973;210:232-41. in-flight and ensuring that there is appropriate calculation of oxygen supplies for the trip, ground time and unexpected delays. While the goal is to make air travel for the oxygen user easier and the process simpler, there will be increased responsibility for the patient, physician and respiratory therapist to make careful plans for each traveller. Resolution of these issues will take time but should lead to the development of a consistent national policy.

ACKNOWLEDGEMENTS: The authors thank Dr Henry Gong $\mathrm{Jr}$, Professor of Medicine, University of Southern California, for his invaluable support, suggestions and manuscript review.

17. Gong H Jr. Air travel and oxygen therapy in cardiopulmonary patients. Chest 1992;101:1104-13.

18. Skjenna OW, Evans JF, Moore MS, Thibault C, Tucker AG. Helping patients travel by air. Can Med Assoc J 1991;144:287-93.

19. Luft UC. Physiologic alterations of altitude in aviation. In: Gordon, BL, Careleton RA, Faber LP. Clinical Cardiopulmonary Physiology, 3rd edn. New York: Grune and Stratton, 1969:613-48.

20. Luft UC. Aviation physiology: The effects of altitude. In: Fenn WO, Rahn H. Handbook of Physiology: Section 3. Washington: American Physiological Society, 1965;2:1099-145.

21. Medical aspects of transportation aboard commercial aircraft. AMA Commission on Emergency Medical Services. JAMA 1982;247:1007-11.

22. Gong H Jr, Mark JA, Cowan MN. Preflight medical screening of patients. Analysis of health and flight characteristics. Chest 1993;104:788-94.

23. McFarland RA. Human factors in relationship to the development of pressurized cabins. Aerospace Med 1971;12:1303-18.

24. Lenfant C, Sullivan K. Adaptation to high altitude. N Engl J Med 1971;284:1298-309.

25. Coates G, Gray G, Mansell A, et al. Changes in lung volume, lung density, and distribution of ventilation during hypobaric decompression. J Appl Physiol 1979;46:752-5.

26. Speizer C, Rennie CJ, Breton H. Prevalence of in-flight medical emergencies on commercial airlines. Ann Emerg Med 1989;18:26-9.

27. Cummins RO, Chapman PJ, Chamberlain DA, Schubach JA, Litwin PE. In-flight deaths during commercial air travel. How big is the problem? JAMA 1988;259:1983-8.

28. Cummins RO, Schubach JA. Frequency and type of medical emergencies among commercial air travellers. JAMA 1989;261:1295-9.

29. Gong H Jr, Tashkin DP, Lee EY, Simmons MS. Hypoxia-altitude stimulation test. Evaluation of patients with chronic airway obstruction. Am Rev Respir Dis 1984;130:980-6. 


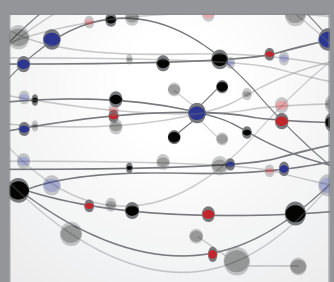

The Scientific World Journal
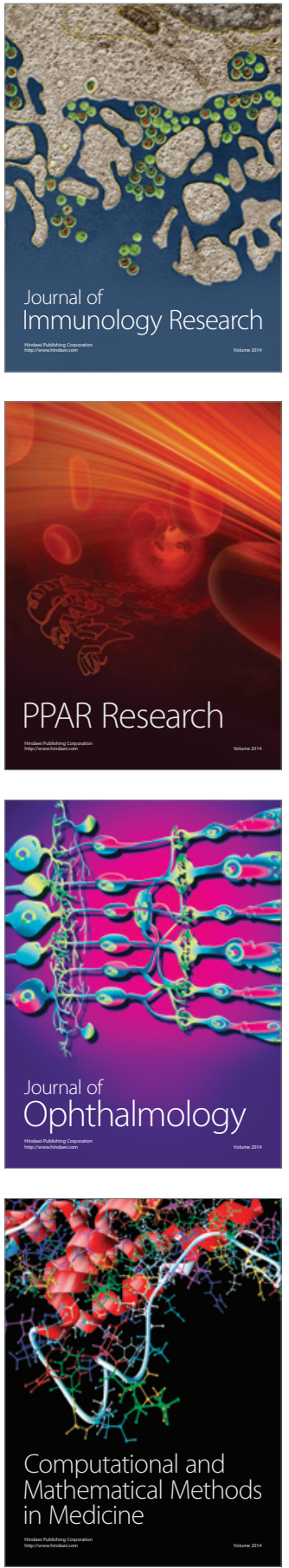

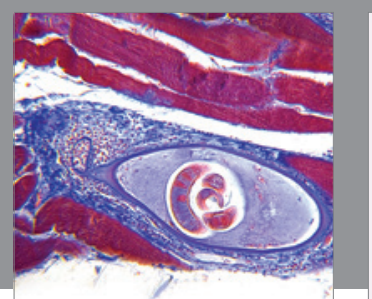

Gastroenterology Research and Practice

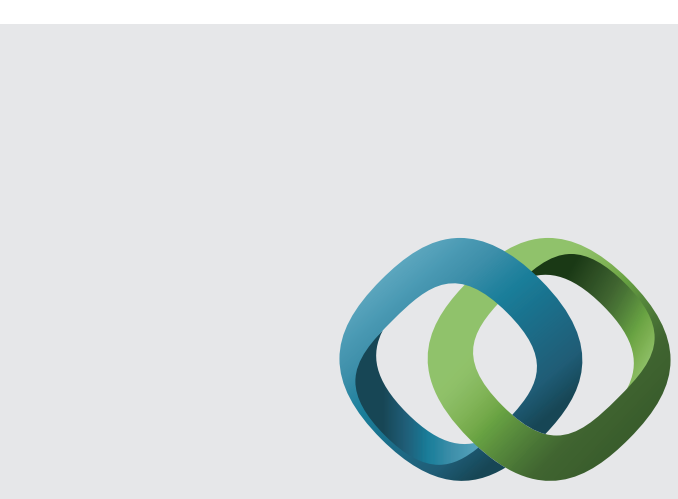

\section{Hindawi}

Submit your manuscripts at

http://www.hindawi.com
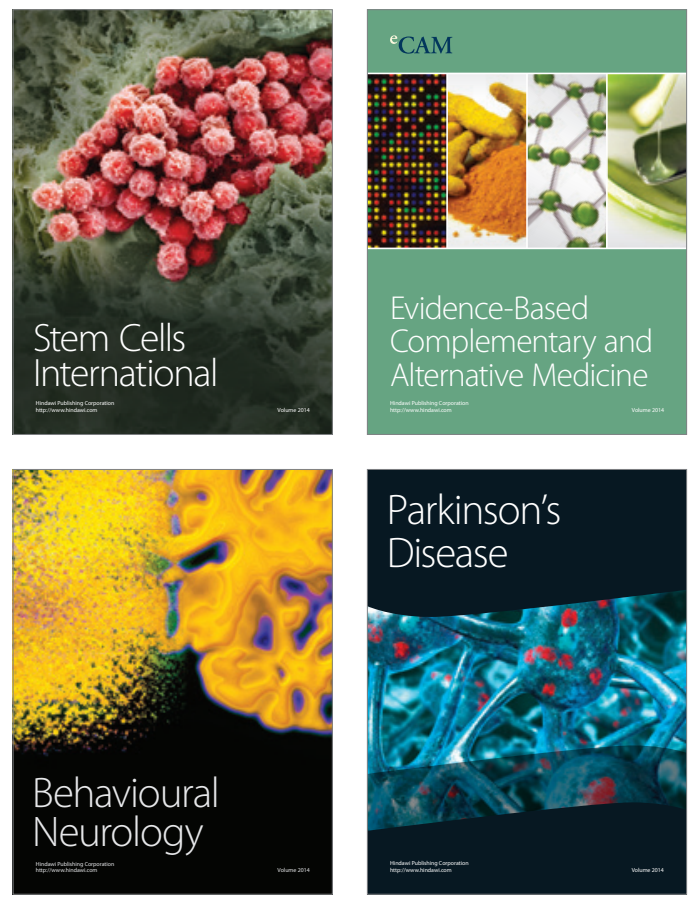
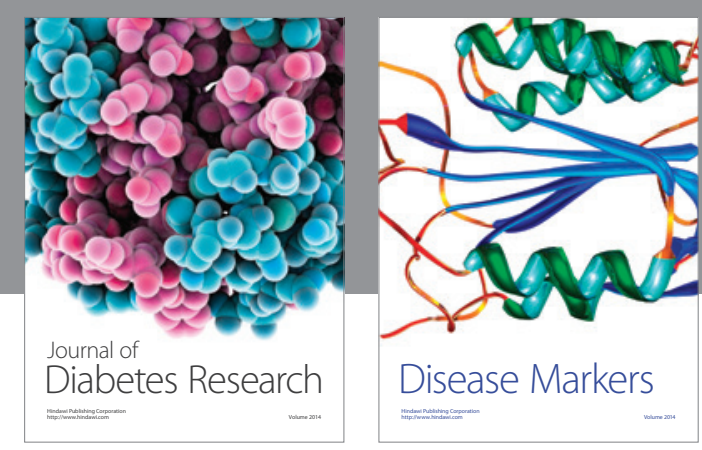

Disease Markers
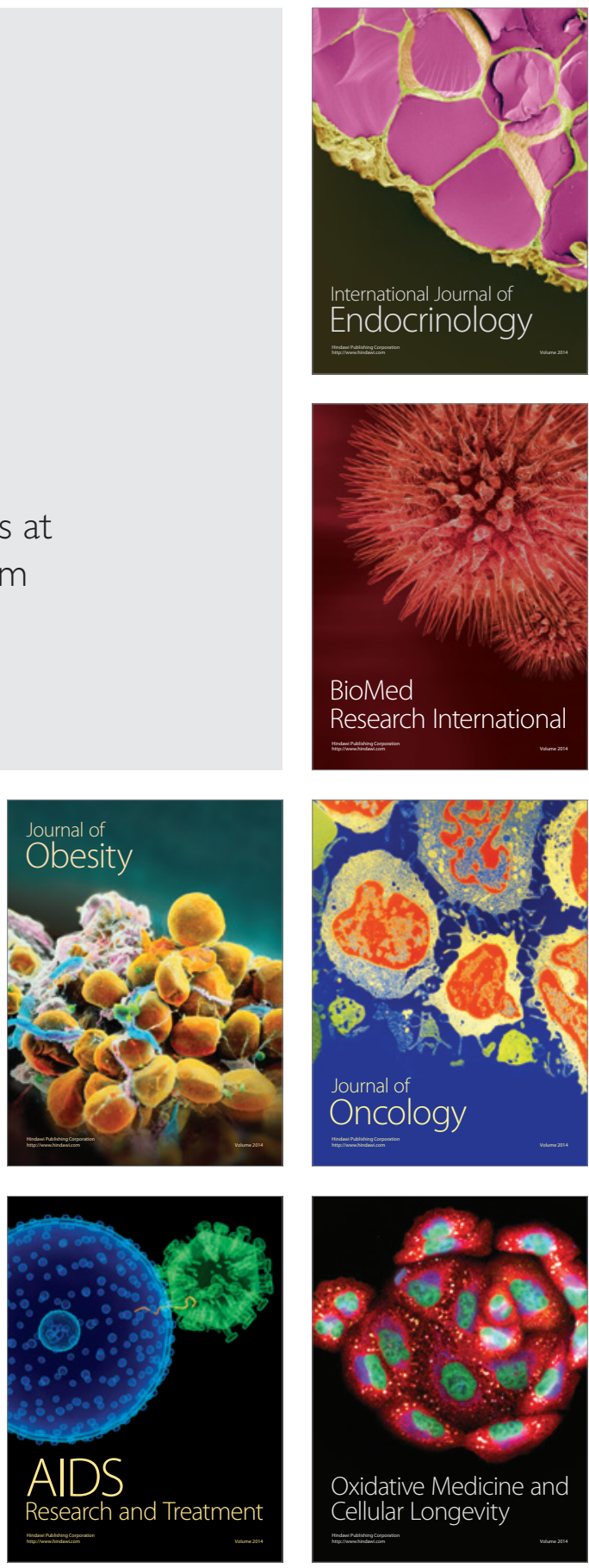